\title{
VIOLÊNCIA SEXUAL INFANTOJUVENIL: O QUE DIZEM OS DOCUMENTOS DO JUIZADO?
}

\begin{abstract}
José Wilson de Lima
Mestre em Psicologia Social pela Universidade Federal da Paraíba. Pesquisador integrante do Núcleo de Pesquisa e Estudos sobre o Desenvolvimento da Infância e Adolescência - NUPEDIA. Bolsista PIBIC à época de realização da pesquisa.

Maria de Fátima Pereira Alberto

Professora Associada do Departamento de Psicologia e do Programa de Pós-Graduação em Psicologia Social da Universidade Federal da Paraíba. Doutora em Sociologia pela Universidade Federal de Pernambuco. Coordenadora do Núcleo Pesquisa e Estudos sobre o Desenvolvimento da Infância e Adolescência (NUPEDIA) da UFPB.
\end{abstract}

Psicóloga pela Universidade Federal da Paraíba. PesquisadorA integrante do Núcleo de Pesquisa e Estudos sobre o Desenvolvimento da Infância e Adolescência - NUPEDIA. Bolsista PIBIC à época de realização da pesquisa.

Kahyna Leite Brito

Psicóloga pela Universidade Federal da Paraíba

Suzany Ludimila Gadelha e Silva

Mestre em Psicologia pela Universidade Federal de do Rio Grande do Norte. Psicóloga pela Universidade Federal da Paraíba.

\begin{abstract}
Resumo
Os objetivos deste artigo são caracterizar os casos de violência sexual contra crianças e adolescentes nos registros de denúncias, notificações e processos no Juizado da Infância e Juventude do município de João Pessoa e analisar os riscos referentes às decisões, aos procedimentos e aos processos que não garantem a proteção e efetivação dos direitos fundamentais. Utilizou-se para coleta de dados um protocolo de pesquisa analisado a partir da análise de conteúdo temática e frequencial. Os fatores de riscos caracterizam-se entre circunstâncias de vida que antecedem a violência sexual e também são decorrentes dos encaminhamentos que sucederam a denúncia. Foram identificados: 30 casos de violência sexual, ocorridos em maior número em instituições sob a responsabilidade do Estado; riscos de negligência, exploração e outras formas de violências; falta de informações nos processos sobre agressores, denúncia, encaminhamento e responsabilização. Os procedimentos e processos não conseguem ser punitivos, educativos ou resolutivos e causam prejuízos às vítimas, à dignidade e aos seus direitos fundamentais.

Palavras-chave: violência sexual; fatores de riscos; infância e adolescência.
\end{abstract}




\title{
CHILD AND YOUTH SEXUAL VIOLENCE: WHAT DO THE DOCUMENTS FROM THE COURT SAY?
}

\begin{abstract}
This article has as objectives to characterize the cases of sexual violence against children and adolescents found in the records of complaints, notices and prosecutions at the Child and Youth Court in the county of João Pessoa and to analyze the risks to the victims of such violence regarding the decisions, procedures and prosecutions that do not guarantee the protection and enforcement of fundamental rights. The instrument used to collect data was a research protocol analyzed by frequency and thematic content analysis. The risk factors are characterized among life circumstances that precede the sexual violence and are originated due to the referrals that happened after the complaint. 30 cases of sexual violence were found, most of them happened inside institutions under the State's responsibility; there were also risk of negligence, exploitation and others forms of violence; lack of information in the documents about aggressor, complaint, referral and accountability. The procedures and prosecutions are not able to punish, educate or solve the issue and can cause damage to dignity, to the victims and their fundamental rights.
\end{abstract}

Keywords: sexual violence; risk factors; childhood and adolescence.

\section{VIOLENCIA SEXUAL CONTRA NIÑOS Y ADOLESCENTES: ¿QUE DICEN LOS DOCUMENTOS DEL TRIBUNAL?}

\begin{abstract}
Resumen
Los objetivos de este artículo son caracterizar los casos de violencia sexual contra niños y adolescentes en los registros de quejas, notificaciones y procedimientos en el Tribunal de la Infancia y Juventud de João Pessoa y analizar los riesgos para las víctimas de este tipo de violencia relacionados con las decisiones, los procedimientos y los procesos que no garantizan la protección y la ejecución de los derechos fundamentales. El instrumento utilizado para la recolección de datos fue un protocolo de investigación analizado a partir del análisis de contenido temático y de frecuencia. Los factores de riesgo se caracterizan entre las circunstancias de vida anterior a la violencia sexual y que derivan de las remisiones posteriores a la denuncia. Fueron encontrados 30 casos de violencia sexual ocurrido en mayor número en las instituciones bajo la responsabilidad del Estado; también riesgo de abandono, explotación y otras formas de violencia; hay ausencia de información en los procesos sobre los agresores, el informe y la responsabilidad. Los procedimientos y procesos no son capaces de punir, educar o resolver el problema y causan daños a la dignidad, a las víctimas y a sus derechos fundamentales.
\end{abstract}

Palabras clave: violencia sexual; factores de riesgo; infancia y adolescencia.

\section{INTRODUÇÃO}

Os objetivos deste artigo são caracterizar os casos de violência sexual contra crianças e adolescentes nos registros de denúncias, notificações e processos no Juizado da Infância e Juventude do município de João Pessoa e analisar os riscos referentes às decisões, aos procedimentos e aos processos que não garantem a proteção e a efetivação dos direitos fundamentais 
Entende-se por violência sexual todas as formas através das quais crianças e adolescentes são usados por adultos para atividades de caráter sexual, com ou sem violência, envolvendo ou não pagamento (Faleiros \& Faleiros, 2007). Dunaigre (1999) destaca a participação de um adulto ou de alguém com uma diferença mínima de idade de cinco anos de sua vítima. Tais práticas configuram-se como uma transgressão legal e violação de direitos à liberdade individual da população infantojuvenil (Leal, 1999).

A violência sexual consiste em formas variadas de interações sexuais, toques, manipulação (da genitália, mama, ânus), carícias, sexo oral, relações com penetração (genital ou anal), voyerismo, exibicionismo e pornografia. Estas interações sexuais são impostas às crianças ou aos adolescentes pela violência física, ameaças, assédio, sedução ou indução de sua vontade (Habigzang, Koller, Azevedo \& Machado, 2005).

A violência sexual caracteriza-se por uma relação de poder abusiva (Faleiros \& Campos, 2000). A violência sexual contra crianças e adolescentes é compreendida como abusiva porque ocorre uma transgressão dos limites, um abuso de poder estabelecido em uma relação que envolve atores com poderes desiguais de conhecimento, autoridade, experiência, maturidade, recursos e estratégias (Faleiros, 2000; Leal, Bontempo, Bosetti, \& César, 1995). De um lado existe uma pessoa em posição de poder, de autoridade ou força física e do outro uma pessoa que - devido ao seu desenvolvimento ou imaturidade - é incapaz de entender a totalidade dos elementos constitutivos da relação da natureza do contato sexual e, mesmo quando entende, não está apta a concordar (Amazarray \& Koller, 1998). O abuso sexual pode ser tanto extrafamiliar como intrafamiliar. O intrafamiliar envolve relação sexual entre pessoas com grau próximo de parentesco sanguíneo ou por afinidade (Poli, 2001). O extrafamiliar é quando incide fora do seio familiar, ou seja, o abusador é alguém com quem não se tem grau de parentesco algum (Libório, 2003) e pode ou não envolver pagamento. Quando envolve pagamento configura-se como exploração comercial.

A Exploração Sexual Comercial abrange as modalidades turismo sexual (deslocamento de pessoas de suas regiões de origem com o objetivo de envolvimento sexual), tráfico e venda de pessoas (para propósitos sexuais) e pornografia infantil (representação, distribuição ou uso de material, exibição, através de quaisquer meios, de criança engajada em atividades sexuais) (End 
Children Prostitution, Pornography and Trafficking for Sexual Purpose [ECPAT], 2006).

A violência sexual causa danos biopsicossociais às crianças e aos adolescentes, incluindo as falhas no ato de proteção, a conivência e a omissão (Warburton, 2001). As consequências dependem de uma série de fatores: (a) da idade, (b) do tipo de violência, (c) do tipo de relação entre vítima e abusador. E tanto pode originar-se de uma situação de risco como pode conduzir ao risco.

O termo risco tem sido, a partir do Estatuto da Criança e do Adolescente (ECA) de 1990, associado aos estudos sobre desenvolvimento humano (Horowitz, 1992). Por situação de risco pessoal e social entende-se a condição em que se encontram crianças e adolescentes que, por suas circunstâncias de vida, estão expostos a um conjunto de experiências relacionadas a privações de ordem afetiva, cultural e socioeconômica que desfavorecem o pleno desenvolvimento biopsicossocial (Lescher et al., 2004).

Usa-se a categoria riscos pelo fato de que ela permite o mapeamento de condições que são potencialmente prejudiciais ao desenvolvimento de crianças e adolescentes por decorrerem da violência em si ou de outros fatores a ela relacionados. A noção de risco está relacionada às condições de crescimento, não se focalizando apenas os fatores imediatos, mas também aqueles que ameaçam o seu desenvolvimento ao longo do tempo (Meirelles, 1998). Deste modo, riscos de exposição às drogas, perigos à formação moral, afastamento da família e da comunidade são fatores que pela sua presença podem contribuir para o aparecimento de enfermidades, danos físicos, psicológicos, sociais e de cidadania (Forastieri, 1997).

No caso dos riscos à cidadania, incluem-se aqueles que, por ação ou omissão da sociedade ou do Estado (Art. 98 do ECA), resultem em lesão ao direito e que se constituam em violação da qual pode resultar um fator desfavorável ao desenvolvimento. Incluem-se as situações que se desencadeiam em processos de exclusão social, nos moldes abordados por Zaluar (1997), como uma manifestação de injustiça distributiva que se revela quando pessoas são sistematicamente excluídas dos serviços e das garantias oferecidas ou asseguradas pelo Estado, pensadas como direitos de cidadania. Em tais contextos a vitimização pela violência se constitui para crianças e adolescentes em situações de riscos. 
A concepção de risco apresentada aqui parte de duas perspectivas: a primeira propõe uma noção de risco enquanto evento probabilístico de algo que pode ou não acontecer, mas que, ainda assim, se reconhece um perigo iminente, isto é, adota uma noção de algo que pode ser desfavorável; a segunda quando o risco ao qual se está exposto ocorre e, consequentemente, resulta em dano. Dessa forma, a exposição a um risco pode, ou não, ter implicações negativas; a segunda propõe uma noção de risco que considera que a exposição a determinados riscos invariavelmente terá consequências negativas (Lescher et al., 2004).

Os fatores de risco são eventos negativos que aumentam a probabilidade de o indivíduo apresentar problemas físicos, psicológicos e sociais (Paludo \& Koller, 2005). Esses eventos incluem atributos biológicos e ambientais favoráveis à ocorrência de efeitos negativos para o desenvolvimento, que possam comprometer a saúde, o bem-estar nas áreas emocionais e cognitivas, e o desempenho social da criança. Entende-se como fatores de risco todas as modalidades de violência doméstica, violência física, negligência, violência psicológica e violência sexual (Maia \& Willams, 2005).

No caso de crianças e adolescentes, por ainda estarem em processo de construção, os riscos estão relacionados não só aos fatores imediatos, mas a todos aqueles que possam trazer consequências ao longo do tempo, para o desenvolvimento, para o crescimento e para a qualidade de vida. Nesse sentido, pode-se compreender que a violência sexual contra crianças e adolescentes tanto pode resultar de certas condições de vida como, uma vez ocorrida, a violência pode levar a outros riscos.

Nessa mesma linha de que a violência sexual pode levar a outros riscos, pesquisas têm mostrado que, mesmo quando a violência é denunciada, pode se constituir em fator de risco (Costa, Carvalho, Bárbara, Santos, Gomes \& Sousa, 2007; Habigzang et al. 2005; Machado, Lueneberg, Régis \& Nunes, 2005), uma vez que os encaminhamentos jurídicos não acontecem a termo, não contemplam todos os casos identificados, não percorrem todas as esferas e não julgam, nem penalizam todos os agressores, o que revitimiza crianças e adolescentes. O risco da revitimização decorre "das exigências jurídicas que desconsideram as dimensões psicológica e social que configuram tal fenômeno" (Habigzang et al. 2005, p. 344). Machado et al. (2005) identificaram a ausência de informações, comprometendo a análise dos casos, a assistência a ser prestada, o diagnóstico 
precoce dos fatores de riscos e a penalização dos envolvidos. Costa et al. (2007) identificaram a falta de registros de informações nos conselhos tutelares, o que impossibilitou a análise desses procedimentos. A pesquisa também mostrou que nem todos os casos foram encaminhados, nem todos foram acompanhados e poucos foram à audiência para apontar dificuldades quanto à adequação do atendimento na Rede que compõe o sistema de garantia de direitos, o que revela revitimização de crianças e adolescentes.

Para garantir o direito e defender crianças e adolescentes vítimas de violência, o Brasil dispõe de ampla Legislação na qual se contempla um conjunto de ações e instituições. Dentre as Leis destaca-se o Estatuto da Criança e do Adolescente (Estatuto da Criança e do Adolescente [ECA], 2005). O ECA é composto de um conjunto de artigos entre os quais: Artigo $3^{\circ}$ (direitos fundamentais), $4^{\circ}$ (define responsáveis pela efetivação dos direitos), $5^{\circ}$ (define na forma da lei a punição para quem atentar contra o direito fundamental), $7^{\circ}$ (assegura o direito às políticas públicas), 13 (fixa o Conselho Tutelar como defensor dos direitos), 16 (direito à liberdade de ir e vir), 17 (direito à inviolabilidade da integridade física), 18 (estabelece o dever de todos de zelar pela dignidade), 60 (proíbe o trabalho infantil), 82 (proíbe a hospedagem de criança ou adolescente em hotel e motel sem a autorização dos responsáveis), 85 (proíbe a saída do país em companhia de estrangeiros domiciliados no exterior sem autorização judicial), 86 (estabelece que a Política de Atendimento deve ser efetivada através de uma Rede de Proteção), 98 (estabelece medidas de proteção quando os direitos forem ameaçados ou violados), 101 (define as medidas a serem determinadas pela autoridade competente), 125 (define 0 papel do Estado), 129 (define as medidas a serem adotadas pelo Estado), 130 (define as medidas a serem adotadas na hipótese dos pais ou responsáveis cometerem o abuso sexual), 131 (define Conselho Tutelar), 136 (determina atribuições do Conselho Tutelar), 146 (define competências do Juiz), 148 (define a competência da Justiça da Infância e Juventude de aplicar medidas cabíveis aos casos encaminhados pelos Conselhos Tutelares para as medidas protetivas tomadas por aqueles quando os direitos forem violados ) 149 (define competências da autoridade judicial), 151 (define competências da equipe interprofissional subordinada à autoridade judicial), 241 (tipifica os crimes de pornografia), 244 A (tipifica a exploração sexual como crime). 
Compõem a Rede de Proteção para efetivar a Política de Atendimento dos direitos da criança e do adolescente as seguintes entidades: Conselhos de Direitos da Criança e do Adolescente, Conselhos Tutelares, Fundos dos Direitos da Criança e do Adolescente, Varas da Infância e da Juventude, Promotorias da Infância e Juventude, Delegacias de Proteção à Criança e ao Adolescente, Fóruns dos Direitos da Criança e do Adolescente, Centros de Defesa, Defensoria Pública, Secretarias de governo estaduais e municipais executoras de políticas públicas, e Organizações não-governamentais.

No contexto da política de atendimento, o Estatuto garante o acesso à Justiça de toda criança ou adolescente, através da Defensoria Pública, do Ministério Público e do Poder Judiciário (Sêda, 1991). O Estatuto estabelece quais as funções do Juiz, dos seus serviços auxiliares, fixa procedimentos especiais para os casos de: perda e suspensão do pátrio poder; destituição da tutela; colocação em família substituta; apuração de ato infracional atribuído a adolescente; apuração de irregularidades em entidades de atendimento; apuração de infração administrativa às normas de proteção à criança e ao adolescente.

No que se refere ao dever do Poder Judiciário, Motti (2005) diz que cabe ao Poder Judiciário a responsabilidade de corrigir judicialmente situações que revelem violação de direitos de pessoas por outra pessoa, por grupos de pessoas, por instituições públicas ou privadas ou ainda por dirigentes institucionais, seja do governo, seja da sociedade. O Poder Judiciário é formado por um conjunto de autoridades com o poder de julgar e que representa o Estado, na missão de aplicar as leis, vigiar sua execução e reparar violações às relações jurídicas.

Sempre que ocorrer a violação dos direitos da criança e do adolescente, devem ter início as ações dos Conselheiros Tutelares através das medidas protetivas conforme reza o artigo 98, cujas atribuições encontram-se previstas no artigo 136, as quais podem ser demandadas por uma denúncia. São as denúncias que mobilizam a apuração dos fatos para se certificar da situação em que se encontra a criança. Sendo a denúncia procedente, é aberto um procedimento que tem como percurso o Ministério Público e a Justiça (comum ou especial, dependendo da violação e do autor da violência) (Conselho Nacional dos Direitos da Criança e do Adolescente [CONANDA], 2007). 
A Justiça da Infância e Adolescência é competente para: apurar atos infracionais atribuído a adolescente, aplicando as medidas cabíveis e quando se tratar da violência sexual contra a criança e o adolescente (Art 98 - medidas de proteção quando os direitos forem violados); aplicar penalidades administrativas nos casos de infrações contra norma de proteção à criança ou ao adolescente; assim como proceder decisões em relação à guarda, tutela e destituição do pátrio poder (Art. 148), nos casos em que a violência sexual envolve, de algum modo, os próprios pais ou responsáveis.

Nos casos de Apuração de Ato Infracional Atribuído a Adolescente conforme reza o ECA "a autoridade judiciária não aplicará qualquer medida, desde que reconheça, na sentença, não haver prova da existência do fato" (Art 198). Para a defesa dos direitos de crianças e adolescentes aplicam-se ações previstas em outras normas (Art 212), tais como Código de Processo Civil, Código de Processo Penal, o que pode significar que a competência para a penalização dos envolvidos, no caso de adultos se dará em outras instâncias.

Todavia a literatura da conta de que a atuação do Estado brasileiro, nos casos de violência sexual contra crianças e adolescentes, no âmbito da justiça, embora represente avanços, ainda não é resolutiva. É o que revela Lima e Deslandes (2011) em pesquisa comparativa EUA e Brasil. Os EUA estabeleceram a notificação compulsória nos casos de violência contra crianças e adolescentes desde 1970. As instituições receptoras das notificações e investigadoras variam de um estado para outro. De modo que as notificações podem ser feitas ao departamento de Serviços Sociais ou à polícia. As investigações podem ser conduzidas pelos centros de proteção à criança, por uma agência de aplicação da lei, ou por ambas as agências. Todos os estados priorizam a punição criminal em suas ações. Diferentemente da realidade brasileira, analisam as autoras, que apesar de reconhecer a importância de responsabilização legal - não consegue implementar mecanismos efetivos, não consegue ser resolutiva, há equívocos nos procedimentos adotados em função da notificação, da atuação dos Conselhos Tutelares e fragilidade da rede de proteção.

Silva, Ferriani e Silva (2012) chegam a conclusões semelhantes em pesquisa com profissionais (juiz, assessores, oficial de justiça, técnicos judiciários e analistas judiciários) que atuam nas Varas dos Crimes contra a Criança e o Adolescente, no Tribunal de Justiça de Pernambuco. Os participantes identificaram o Poder Judiciário como a última instância dos casos de violência 
sexual intrafamiliar contra crianças e adolescentes e apesar das diferentes formações compartilham a percepção de que o Poder Judiciário é a instância final de uma trajetória penosa e preocupam-se em dar uma resposta aos usuários. As autoras concebem que a responsabilização desempenha as funções de punir e educar. Para as vítimas funciona como reparação e ação preventiva do agravamento dos danos. Para a sociedade funciona na prevenção da ocorrência de novos casos, contribui para interromper comportamentos violentos contra crianças e adolescentes e estimula a sociedade a buscar a punição legal. Mas os dados identificados pelas autoras são de morosidade, um indicativo de ineficiência e falta de efetividade do Poder Judiciário. Que se constitui em injustiça e que causa prejuízos às vítimas.

\section{MÉTODO}

Utilizou-se nesse estudo a análise de documentos (Minayo, 2007). A pesquisa foi realizada, após autorização e aprovação do comitê de ética (conforme Resolução 196 do Conselho Nacional de Saúde), e mediante consentimento do Juiz responsável, nos arquivos (os documentos denominados autos processuais) da $2^{a}$ Vara do Juizado da Infância e Juventude de João Pessoa, cuja escolha deu-se pela competência que é destinada no ECA para a Justiça em aplicar medidas de proteção sempre que os direitos de crianças e adolescentes forem violados.

\section{Instrumento}

O instrumento utilizado para a coleta dos dados foi um protocolo de pesquisa elaborado pela equipe de pesquisa com questões que levantavam informações sobre perfil da criança e do adolescente, da família e do agressor, características da violência sexual, outras formas de violência sofridas pela criança ou adolescente, sobre a denúncia, o processo e as redes de encaminhamento.

\section{Procedimentos}

A coleta de dados seguiu três passos:

10 passo: verificação das caixas-arquivo contendo os processos. Existiam 200 caixas-arquivo enumeradas, que estavam armazenadas em estantes, ou empilhadas no chão. O arquivamento não é feito seguindo-se uma cronologia, uma vez que os processos são arquivados conforme vão sendo 'baixados' (termo usado pelos funcionários para se referir aos processos que foram julgados e que 
devem ser arquivados) pelos juízes, podendo haver processos de diferentes anos em uma mesma caixa. Decidiu-se iniciar a verificação das caixas em ordem decrescente. Depois de identificadas, as caixas foram transportadas pelos pesquisadores para outra sala, onde havia condições mais adequadas para a realização da pesquisa.

$2^{\circ}$ passo: identificação dos casos de violência sexual. O critério utilizado para a identificação foi verificar na capa do processo se havia referência à violência sexual. Caso na capa do processo não ficasse claro a que o processo se referia, olhava-se nas fichas que faziam parte dele.

30 passo: coleta dos dados no processo. Inicialmente leu-se todo o processo para que se compreendesse melhor o caso. Em seguida, respondeu-se cada uma das questões constantes no instrumento, a partir das informações nos processos. O tempo de coleta variou, pois dependia da quantidade de informações e fichas contidas no processo. Após a verificação de 200 caixas, identificaram-se 30 casos de violência sexual contra crianças ou adolescentes.

Análise dos dados

Ao fim da coleta, os protocolos de investigação foram submetidos a tratamento, no qual se usou a análise de conteúdo temática de Bardin (2007). Para isso, fez-se uma leitura das questões para a identificação das unidades temáticas, o agrupamento e a criação das categorias enfatizando a presença e a frequência do tema através de inferências estatísticas. Todo o processo foi realizado por um grupo de pesquisadores que agia mediante consenso, considerando para tal os referenciais teóricos utilizados e as etno-categorias.

\section{RESULTADOS}

A análise dos registros de denúncias, notificações e processos no Juizado da Infância e Juventude no município de João Pessoa permitiu identificar 30 casos de violência sexual contra crianças e adolescentes, conforme Tabela 1.

A caracterização dos casos de violência sexual revela que esta atinge meninos e meninas com idades entre 02 e 07 anos. Todavia, revela que os meninos são em maior número e articula-se com o fato de residir em instituição, uma vez que $16(53,3 \%)$ residem em instituição e 12 (40\%) residem com a família. Os dados revelam que se constitui como uma situação de risco maior do que residir com a família. 
Tabela 1.

Perfil da vítima nos casos de violência sexual identificados nos registros

\begin{tabular}{ccc}
\hline Variáveis & $\mathrm{N}$ & $\%$ \\
\hline Idade & & \\
02 a 07 & 05 & 16,6 \\
08 e 12 & 05 & 16,6 \\
13 e 17 & 19 & 63,3 \\
Não há informação & 01 & 03,3 \\
\hline Total & 30 & 100 \\
\hline Sexo & & \\
Masculino & 19 & 63,3 \\
Feminino & 11 & 36,7 \\
\hline Total & 30 & 100
\end{tabular}

Em todos os casos de violência sexual identificados nos registros não há a informação sobre a etnia da vítima. E $20(66,7 \%)$ não apresentam informação sobre a escolaridade. Dos 10 casos que têm a informação, cinco $(16,7 \%)$ não são alfabetizados; três $(9,9 \%)$ têm o ensino fundamental II; e dois $(6,6 \%)$ têm o ensino médio incompleto.

Tabela 2.

Perfil do agressor nos casos de violência sexual identificados nos registros

\begin{tabular}{ccc}
\hline Características & $\mathrm{N}$ & $\%$ \\
\hline Idade & & \\
13 a 18 & 25 & 83,3 \\
19 e 30 & 04 & 13,3 \\
31 & 01 & 03,3 \\
\hline Total & 30 & 100 \\
\hline Relação do agressor com a & & \\
vítima & 19 & 63,3 \\
Amigos/Vizinhos/Conhecidos & 04 & 13,3 \\
Desconhecidos & 04 & 13,3 \\
Namorados/Companheiros & 01 & 03,3 \\
Pai por afinidade & 02 & 06,7 \\
Não há informação & 30 & 100 \\
\hline Total & & \\
\hline
\end{tabular}


A Tabela 2 mostra na caracterização dos casos de violência sexual que o agressor é homem, jovem, em sua maioria próxima da vítima e cometeu além da violência sexual outras formas de violências, destacando-se a violência física, com $12(40 \%)$ casos. No entanto, não é possível analisar em detalhe essas outras formas de violências porque em $17(56,7 \%)$ casos não consta nos documentos o registro de informações sobre outras formas de violência.

Já em relação à etnia do agressor dos 30 casos analisados, $29(96,7 \%)$ não apresentam a informação. A etnia do agressor consta em apenas um (3,3\%) dos casos e é branca. Ao se analisar a relação do agressor com a vítima, consta-se que em dois $(6,7 \%)$ casos não há informações.

Caracterização da violência sexual

Nos casos identificados havia uma tipificação nos processos registrados pelas instituições que acolheram as denúncias e fizeram o encaminhamento ou pela próprio Juizado, conforme mostra a Tabela 3. Embora faltem várias informações, é possível caracterizar, em parte dos casos, a violência sexual quanto à forma como ocorreu, circunstâncias, local e frequência.

Tabela 3.

Caracterização da violência sexual nos casos identificados nos registros

\begin{tabular}{ccc}
\hline Variáveis & $\mathrm{N}$ & $\%$ \\
\hline $\begin{array}{c}\text { Tipificação da violência } \\
\text { Atentado violento ao pudor }\end{array}$ & 18 & 60,0 \\
Conjunção carnal & 05 & 16,7 \\
Estupro & 03 & 10,0 \\
Ato libidinoso & 02 & 06,7 \\
Não há informação & 02 & 06,7 \\
\hline Total & 30 & 100 \\
\hline Como ocorreu a violência & & 60,0 \\
Com violência física & 18 & 26,7 \\
Com sedução & 08 & 10,0 \\
Com violência psicológica & 03 & 03,3 \\
Com assédio & 01 & 100 \\
\hline Total & 30 &
\end{tabular}


Tabela 3.

Caracterização da violência sexual nos casos identificados nos registros (cont.)

Circunstâncias

Com outros adolescentes

10

33,3 envolvidos

Não há informação

$$
07
$$

Enquanto a família dormia

13,3

Ausência da mãe

03

10,0

Na rua desacompanhado

02

06,7

Aos cuidados do agressor

02

06,7

Mãe estava ocupada em casa

01

03,3

Em visita ao agressor

0103,3

\begin{tabular}{ccc}
\hline Total & 30 & 100 \\
\hline Local & 10 & 33,3 \\
No centro educacional & 05 & 16,7 \\
No centro de atividades \\
ocupacionais & 05 & 16,7 \\
Na rua desacompanhado & 03 & 10,0 \\
Residência do agressor & 03 & 10,0 \\
Instituição que frequenta & 02 & 06,7 \\
Residência da vítima & 01 & 03,3 \\
Motel & 01 & 03,3 \\
Não há informação & 30 & 100 \\
\hline Total & 13 & 43,3 \\
Frequência & 09 & 30,3 \\
Uma única vez & 08 & 26,4 \\
Não há informação & & 100 \\
Várias vezes por semana, & 30 & \\
meses ou anos & & \\
\hline Total & 03 & \\
\hline
\end{tabular}

Em relação às circunstâncias, sete $(23,3 \%)$ não têm essa informação. Os dados revelam que na época em que ocorreu a violência $16(53,3 \%)$ crianças e adolescentes moravam em instituições e 12 (40\%) moravam com a família. Todavia, quando se verifica no processo informações acerca do local onde ocorreu a violência sexual em 18 (60\%) casos, as violências ocorreram em instituições nas quais a criança ou o adolescente estavam acolhidos ou cumpriam medida socioeducativa. Ou seja, sob a responsabilidade do Estado. 
Em relação a quem da família tomou conhecimento, 18 (60\%) casos não têm a informação. Dentre os que contêm a informação, a genitora tomou conhecimento em cinco $(16,7 \%)$; o genitor em três $(10 \%)$; outros parentes em quatro (13,3\%). Quanto ao que foi feito após a tomada de conhecimento, em 18 (60\%) não há informações; em 12 (40\%) há informações de que fizeram a denúncia. Vale ressaltar que esses 12 (40\%) são exatamente aqueles que moram com as famílias.

Sobre o processo

Quem fez o caso chegar até o Juizado da Infância e Juventude em 17 $(56,7 \%)$ casos foi o Ministério Público; em 10 (33,3\%) foram instituições; um $(3,3 \%)$ foi o Conselho Tutelar; um $(3,3 \%)$ foi um dos genitores e em um $(3,3 \%)$ não contém essa informação no processo. Em relação à porta de entrada, 18 (60\%) dos casos teve a delegacia da infância e juventude como porta de entrada; sete $(23,3 \%)$ dos casos chegaram primeiro ao Ministério Público; dois $(6,7 \%)$ tiveram a própria instituição como porta de entrada; um $(3,3 \%)$ chegou primeiro ao Conselho Tutelar; um (3,3\%) à delegacia distrital; e um $(3,3 \%)$ teve outros lugares como porta de entrada.

No que se refere à trajetória do processo, 18 casos (60\%) passaram pelo Juizado da Infância; oito casos $(26,7 \%)$ passaram pela Delegacia da Infância e Juventude; cinco casos (16,7\%) passaram por outras Delegacias; três casos (10\%) passaram pela Curadoria da Infância e Juventude; três casos (10\%) passaram pela $4^{a}$ Delegacia Distrital; um caso (3,3\%) passou pela Delegacia de repressão a crimes contra a infância e juventude; e um caso $(3,3 \%)$ passou por um dos conselhos tutelares. Vale ressaltar que essa questão identificava o conjunto de instituições pelas quais o processo passou, logo há processos que passaram por várias instituições, motivo pelo qual a soma dos dados é maior que $100 \%$.

Os dados mostram que dos 30 casos analisados, em três (10\%) não há informações sobre o tempo decorrido entre a violência sexual e a denúncia. Dos casos que contém essa informação, 10 (33,3\%) fizeram a denúncia no mesmo dia da violência; seis (20\%), alguns dias após; seis (20\%), 1 a 11 meses após; três $(10 \%), 1$ a 4 meses após; e dois $(6,7 \%)$ denunciaram logo após a descoberta do abuso.

Em relação aos documentos encontrados nos processos, foram considerados os que têm percentuais acima de $10 \%$. Os documentos que mais 
aparecem são: 27 ofícios (90\%); 22 relatórios policiais (73,3\%); 17 termos de declaração (56,7\%); 15 notificações (50\%); 15 laudos de corpo de delito (50\%); 14 termos de audiência (46,7\%); 13 certidões de ocorrência policial (43,3\%); 12 termos de depoimento $(40 \%) ; 12$ despachos $(40 \%) ; 10$ cópias de registro de nascimento $(33,3 \%) ; 10$ termos de apresentação $(33,3 \%) ; 10$ requisições de exames $(33,3 \%)$; sete pareceres psicológicos (23,3\%); seis sentenças $(20 \%)$; quatro laudos médicos $(13,3 \%)$; quatro mandatos de intimação de testemunha $(13,3 \%)$; quatro termos de representação (13,3\%). Nesse caso também procurou-se identificar o conjunto, por isso a soma é maior que $100 \%$.

Em relação ao desenrolar do processo, os dados mostram que dos 30 casos analisados, em nove (30\%) não há informações sobre o desfecho do processo. Dos casos que apresentam essa informação, 13 (43,3\%) foram arquivados; em cinco $(16,7 \%)$ foram abertos inquérito policial e três (10\%) foram encaminhados para outra instituição.

Os dados mostram que dos 30 casos analisados, quatro (13,3\%) não contêm a informação sobre o que ocorreu ao agressor. Dentre os que contêm a informação, nove (30\%) foram internados para medidas socioeducativas; sete $(23,4 \%)$ tiveram remissão instintiva de obrigações; cinco (16,7\%) foram absolvidos; dois $(6,7 \%)$ foram inocentados; nos demais casos, com um $(3,3 \%)$ cada, constam: morreu, retirada a acusação e foi preso.

No que diz respeito às redes de encaminhamentos, $14(46,7 \%)$ fizeram alguma ação, sendo que cinco $(16,7 \%)$ investigaram o caso; quatro $(13,3 \%)$ encaminharam o caso; cinco $(16,7 \%)$ julgaram o caso, e em dois $(6,6 \%)$ não há informações. As redes de encaminhamento relacionadas às instituições de defesa das crianças (Delegacia da Infância e Juventude, Ministério Público, Juizado da Infância e Juventude) foram responsáveis pelas seguintes ações: investigação, encaminhamento e julgamento dos casos que chegaram até elas.

\section{DISCUSSÃO}

Os casos de violência sexual identificados nos registros e processos no Juizado da Infância e Juventude no município de João Pessoa tanto se caracterizam pelo abuso sexual intrafamiliar (em casa, por parte de pais e responsáveis) como extrafamiliar (por desconhecidos) (Poli, 2001; Libório, 2003). Constituem-se em situações abusivas, que atingem a liberdade individual das vítimas (Leal, 1999; Faleiros e Campos, 2000; Faleiros, 2000). Envolvem 
atores com poderes desiguais, (Faleiros \& Faleiros, 2007) mesmo que alguns dos agressores também sejam adolescentes, se configura uma diferença de idade conforme define Dunaigre (1999) e, no caso dos adolescentes, pelo menos de recursos e estratégias (Leal et al., 1995) uma vez que 33, 3\% das violências sexuais envolveram outros adolescentes, ou vários adolescentes, ou seja, o uso de força física por um grupo (Amazarray \& Koller, 1998). Quando tinha como agressores adultos havia uma diferença de conhecimento, autoridade, experiência, maturidade (Faleiros, 2000). A caracterização da violência sexual nos casos nos registros e processos identificados nessa pesquisa também apresentam-se consoante a literatura quanto ao tipo (com ou sem contato) e como ocorreu (com violência, assédio e sedução) (Habigzang, Koller, Azevedo \& Machado, 2005).

Os fatores de riscos identificados nessa pesquisa caracterizam-se entre as circunstâncias de vida que se relacionam aos contextos sociais nos quais se desenvolvem, aos riscos relacionados à violência sexual e aqueles decorrentes dos encaminhamentos que sucederam a denúncia. Há fatores de riscos que não se associam diretamente com a violência sexual e alguns que até são anteriores. Talvez, eles já sejam riscos para que a violência ocorra. São circunstâncias de vida (Lescher et al., 2004) que contribuíram para que essas crianças ou adolescentes fossem institucionalizados, seja em abrigos, seja em instituições educativas para cumprimento de medidas socioeducativas. Há aqueles riscos relacionados à ausência de escolaridade e que desfavorecem o pleno desenvolvimento biopsicosocial (baixo nível de escolaridade e analfabetismo). São riscos que se configuram em situações de exclusão social, que se revela como a falta de acesso aos serviços e garantias asseguradas pelo Estado como um direito de cidadania (Zaluar, 1997).

No que se refere aos fatores de riscos encontrados, conforme definição aqui usada de que riscos são experiências de privação que desfavorecem o desenvolvimento (Lescher et al., 2004), muitos se referem à violação dos direitos garantidos no ECA. Foram encontrados riscos de negligência, exploração e violência (Maia \& Willams, 2005), o que vai de encontro com o Artigo 50 do ECA, que estabelece que nenhuma criança ou adolescente será objeto de qualquer forma de negligência, discriminação, exploração, violência, crueldade e opressão, punido na forma da lei qualquer atentado, por ação ou omissão, aos seus direitos fundamentais. Também se pôde observar que as crianças e 
adolescentes não gozam de todos os direitos assegurados por Lei em condições de igualdade, conforme estabelece o Artigo $3^{\circ}$ do ECA. Assim, ser vítima de violência sexual, física e psicológica ao estar sob a tutela do Estado, cumprindo medida socioeducativa ou em acolhimento, bem como ter o processo de apuração do ocorrido arquivado por falta de provas que possibilitem a penalização do agressor, não se constitui uma oportunidade de se desenvolver (Paludo \& Koller, 2005; Horowitz, 1992) em condições dignas.

Constata-se o risco de não ter à efetivação dos direitos fundamentais e à dignidade (Sarlet, 2009; Silva et al., 2012), visto que se observou que nem a família, nem a comunidade, nem a sociedade, nem o poder público asseguram a efetivação do direito à dignidade, indo de encontro ao que estabelece o Artigo 40 do ECA. Constatou-se também que não é assegurado o acesso às políticas sociais públicas que permitam o desenvolvimento sadio e harmonioso em condições dignas de existência, o que estabelece o Artigo 70 do ECA, pois estar morando ou com a família ou em instituição (em alguns casos já cumprindo medida socioeducativa) há, no caso dessa pesquisa, a vulnerabilidade à situações de riscos, inclusive de violência sexual.

No que se refere aos fatores de riscos encontrados nos processos no Juizado, observa-se que o Estado não garantiu o direito da integridade física dos adolescentes que estavam sob responsabilidade de instituições, contrariando o que está previsto no Artigo 125 do ECA. Identificou-se nos registros a presença de várias formas de violência sexual, tais como a conjunção carnal por estupro e à prática de atos libidinosos sob ameaça, considerados crimes pelo Artigo 213 do Código Penal.

Os dados identificados nos documentos constantes nos processos no Juizado revelam os fatores de riscos para a ocorrência da violência sexual e da prática de atos libidinosos, tanto para crianças e adolescentes que moram com a família, quanto para aqueles que estavam cumprindo medidas socioeducativas ou em acolhimento em alguma instituição. Vale ressaltar que 18 (60\%) das violências ocorreram em instituições nas quais a criança ou adolescente ou estava abrigado ou cumpria medida socioeducativa, ou seja, sob a responsabilidade do Estado. É interessante observar que, em relação a quem da família tomou conhecimento, 18 (60\%) casos não têm a informação e em 18 (60\%) não há informações sobre o que foi feito após a tomada de conhecimento, o mesmo número ou percentual daquele dado de que a violência sexual ocorreu 
em instituição. Além desses, há outros dados cujos números ou percentuais são próximos ou semelhantes: $19(63,3 \%)$ das vítimas são meninos, e em 25 $(83,3 \%)$ o autor tem de 13 a 18 anos.

Em relação à idade, os fatores de riscos existem para crianças e adolescentes entre 02 e 17 anos, mas prevaleceu nas idades entre 13 e 17 anos, do sexo masculino, exatamente naquela parcela maior que está cumprindo medidas socioeducativas. Um motivo para que isso ocorra, talvez seja o fato da maioria dos processos ser de adolescentes que se encontram institucionalizados $(57,1 \%)$. Esses dados também mostram que tanto ter uma instituição $(59,3 \%)$ como responsável, quanto ter os pais $(40,7 \%)$ como responsáveis, existe risco de violência sexual.

No que diz respeito aos agressores, observou-se que $83,3 \%$ dos casos têm entre 13 e 18 anos. O fato da maioria dos casos de violência acontecer em instituições para adolescentes do sexo masculino, também pode explicar a alta incidência de casos de atentado violento ao pudor $(64,3 \%)$.

Observou-se, também, que nos Centros de cumprimento de medidas socioeducativas, tanto os de caráter semiaberto quanto os de caráter privativo, houve a identificação, nos processos pesquisados, de casos de violência sexual, de adolescente contra adolescente, praticados dentro destas instituições, e que se fundamentam como uma forma de punição e consequentemente, uma afirmação das relações de poder que surgem nesses ambientes. Os adolescentes que se recusam a seguir as regras criadas pelos pares, que são impostas pelos mais influentes e aplicadas dentro dos alojamentos, são punidos pela "desobediência", em alguns casos, com o estupro ou ato libidinoso, utilizando, inclusive, objetos como vassouras e frascos de desodorantes. Embora sejam adolescentes, eles impõem-se sobre os outros através da violência sexual, utilizando o grupo do qual fazem parte para, através da força física, submeter outros adolescentes à violência (Faleiros \& Campos, 2000 Faleiros, 2000; Leal et al., Bontempo, Bosetti, \& César, 1995). Diante das dificuldades institucionais de garantir direitos, o que ocorre é a exposição a outros fatores de risco para a violência sexual entre estes adolescentes que cumprem medidas socioeducativas em regime de internação; o que acaba por colocar essa violência ocorrida dentro das instituições como mais um agravante na pena do agressor, eximindo as responsabilidades destas instituições e do Estado, que são os responsáveis por zelar pelo adolescente institucionalizado. 
Outro fator de extrema importância detectado nessa pesquisa foi a falta de informações nos documentos que compõem os processos. Em vários processos faltam nos documentos de denúncia e encaminhamento informações sobre: a escolaridade da vítima, idade da vítima; residência da vítima, responsável pela vítima antes e após a denúncia; em nenhum documento há registro quanto a etnia da vítima; escolaridade do agressor, etnia do agressor, tipificação da violência, circunstâncias em que ocorreu a violência, quem da família tomou conhecimento da violência; outros tipos de violência sofridas; informações do desfecho do processo.

A falta dessas informações pode dificultar 0 atendimento, 0 encaminhamento e a intervenção preventiva para proteger as crianças e adolescentes como também suas famílias. Contudo, esse fator não é exclusivo do município de João Pessoa - PB, já que estudos realizados nos conselhos tutelares em feira de Santana-BA mostram que a falta de informações nos documentos que compõem os processos é uma realidade (Costa et al, 2007; Machado et al., 2005).

A falta de informações nos documentos que chegam ao juizado para compor o processo dificulta a ação da Justiça da Infância e Adolescência cuja ação, segundo o Artigo 98 do ECA, não pode ocorrer se não houver prova da existência do fato. Embora o Juizado da Infância e Adolescência também seja competente para realizar a aplicação de penalidades administrativas nos casos de infrações contra norma de proteção e proceder nas decisões em relação à tutela, guarda ou pátrio poder quando ocorre violência sexual envolvendo pais ou responsáveis, conforme Artigo 148 do ECA, a falta de informações nos processos dificulta a instrução e a correção judicial das situações que violem os direitos de crianças e adolescentes (Motti, 2005). Nesse sentido, a falta de dados se configura como mais um fator de risco, havendo um dano pela revitimização, uma vez que a impunidade também se configura em violência.

Os riscos decorrentes das condições de vida que antecedem o processo somam-se aos riscos decorrentes das decisões, procedimentos e processos que não garantem a proteção e efetivação dos direitos fundamentais. No caso desses últimos riscos, eles resultam em dano à cidadania e lesam um direito fundamental. Além disso, Sarlet (2009), em interpretação dos direitos fundamentais, define que os "detentores do poder estatal formalmente considerados (os órgãos dos Poderes Legislativo, Executivo e Judiciário) se 
encontram obrigados pelos direitos fundamentais e aponta para a necessidade de todos os Poderes públicos respeitarem o âmbito da proteção dos direitos fundamentais" (p.366). Concebe-se neste artigo que a análise dos dados identificados nos documentos revela riscos e danos, sendo estes danos as violações contra a dignidade da pessoa humana. Há a violação dos direitos fundamentais quando: para 18 (60\%) das crianças e adolescentes a violência sexual ocorreu quando estavam em instituições sob a responsabilidade do Estado; não há informações que possibilitem punir e educar. Há dificuldades na implementação de mecanismos efetivos e na resolução dos casos em função da notificação ou da insuficiência de informações (Lima \& Deslandes, 2011). Há também um indicativo de ineficiência e falta de efetividade do Poder Judiciário, que se constitui em injustiça e que causa prejuízos às vítimas (Silva et al., 2012) aos seus direitos fundamentais e a sua dignidade.

\section{CONSIDERAÇÕES FINAIS}

Os dados da pesquisa revelam os riscos e as condições em que se encontram crianças e adolescentes que, por suas circunstâncias de vida, estão expostos a um conjunto de experiências relacionadas à possibilidade de perda, dano ou perigo que desfavorecem o pleno desenvolvimento biopsicosocial. No caso dessa pesquisa os riscos referem-se a situações que podem levar à violência sexual e condições que se somam ou decorrem dela. Há, ainda, outras formas de violência (física, psicológica, negligência, institucional) e revitimização. Entretanto, se sobressaem as violências que vitimizam crianças e adolescentes institucionalizados que, sob a responsabilidade do Estado, não têm seus direitos de integridade física e mental garantidos. Os procedimentos e processos não conseguem ser punitivos, educativos e resolutivos, causando prejuízos às vítimas, à dignidade e aos seus direitos fundamentais.

\section{REFERÊNCIAS}

Amazarray, M. R., \& Koller, S. H. (1998). Alguns aspectos observados no desenvolvimento de crianças vítimas de abuso sexual. Psicologia Reflexão e Crítica, 11(3), 559-578.

Bardin, L. (2007). Análise de conteúdo. Lisboa: Edições 70. 
Conselho Nacional dos Direitos da Criança e do Adolescente [CONANDA] (2007). Conselho Municipal dos Direitos da Criança e do Adolescente e Conselho Tutelar: Orientações para criação e funcionamento. Brasília: Secretaria Especial dos Direitos Humanos.

Costa, M. C. O., Carvalho, R. C., Bárbara, J. F. R. S., Santos, C. A. S. T., Gomes, W. A., Sousa, H. L. (2007). O perfil da violência contra crianças e adolescentes, segundo registros de Conselhos Tutelares: vítimas, agressores e manifestações de violência. Ciênc. Saúde Coletiva, 12(5). Recuperado em 29 de Junho de 2009, de $<$ http://www.scielo.br/scielo.php?script=sci_arttext\&pid=S1413$81232007000500010 \& \operatorname{lng}=$ en\&nrm $=$ iso $>$.

Dunaigre, P. (1999). O ato pedófilo na história da sexualidade humana. In: UNESCO. Inocência em perigo: Abuso sexual de crianças, pornografia infantil e pedofilia na Internet. Rio de Janeiro: Garamond.

End Children Prostitution, Pornography and Trafficking for Sexual Purpose ECPAT (2006). Disponível em http://ecpat.net/eng/CSEC/faq/faq1.asp.

Estatuto da Criança e do Adolescente (2005). Brasília: Senado Federal. Subsecretaria de Edições Técnicas.

Faleiros, E. T. S. (2000). Repensando os conceitos de violência, abuso e exploração sexual de crianças e adolescentes. Brasília: Thesaurus.

Faleiros, V. P., Faleiros, E. S. (2007). Escola que protege: Enfrentando a violência contra crianças e adolescentes. Brasília: Ministério da Educação, Secretaria de Educação Continuada, Alfabetização e Diversidade.

Forastieri, V. (1997). Children at work: Health and safety risks. Geneva: International Labour Office.

Habigzang, L. F., Koller, S. H., Azevedo, G. A., Machado, P. X. (2005). Abuso Sexual infantil e dinâmica familiar: Aspectos observados em processos jurídicos. Psicologia Teoria e Pesquisa, 21(3), 341-348.

Horowitz, F. D. (1992). The concept of risk: A reevaluation. In S. L. Friedman \& M. D. Sigman (orgs). The psychological developmental of birthweight children (pp. 61-88). Norwood: Ablex.

Leal, M. L. P. (1999). A exploração sexual comercial de meninos, meninas e adolescentes na América Latina e Caribe - Relatório final - Brasil. Brasília: CECRIA. 
Leal, M. L. P., Bontempo, D., Bosetti, E., \& César, M. A. (org.). (1995). Exploração sexual de meninas e adolescentes no Brasil. Brasília: UNESCO/Cecria.

Lescher, A. D., Gajcer, B., Bedoian, G., Azevedo, L. M., Silva, L. N., Pernambuco, M. C. A., et al. (2004). Crianças em situação de risco social: Limites e necessidades da atuação do profissional de saúde. Recuperado em 20 abril de 2007, de http://www.projetoquixote.epm.br.

Libório, R. M. C (2003). Desvendando vozes silenciadas: As adolescentes em situação de exploração sexual comercial. Tese de doutorado não-publicada. Instituto de Psicologia da Universidade de São Paulo, São Paulo.

Lima, J. S., \& Deslandes, S. F. (2011). A notificação compulsória do abuso sexual contra crianças e adolescentes: Uma comparação entre os dispositivos americanos e brasileiros. Interface - Comunicação, Saúde, Educação, 15(38), 819-832. Epub 30 de setembro de 2011. Recuperado em 30 de junho de 2014, de http://www.scielo.br/scielo.php?script=sci_arttext\&pid=S141432832011000300016\&lng=pt\&tlng=pt. $10.1590 / S 1414-$ 32832011005000040

Machado, H. B., Lueneberg, C. F., Régis, E. I., \& Nunes, M. P. P. (2005). Abuso sexual: Diagnóstico de casos notificados no município de Itajaí/SC, no período de 1999 a 2003, como instrumento para a intervenção com famílias que vivenciam situações de violência. Texto e Contexto Enfermagem, 14, 54-63.

Meirelles, Z. V. (1998). Vida e trabalho de adolescentes no narcotráfico numa favela no Rio de Janeiro. 1998. 100 p. Dissertação de Mestrado. Escola Nacional de Saúde Pública, Fundação Osvaldo Cruz. Rio de Janeiro.

Minayo, M. C. S. (2007). O desafio do conhecimento: Pesquisa qualitativa em saúde. Hucitec: São Paulo.

Motti, A. J. A. (2005). Infância e adolescência: Direitos, cidadania e inclusão social. In: A. S. Silva, E. Sena, M. C. M. Kassan (org). Exploração sexual comercial de crianças e adolescentes e tráfico para os mesmos fins, pp. 5169. Brasília: OIT.

Poli, M. E. H. (2001). Abuso sexual. Feminina, 29(7). 
Sarlet, I. W. (2009). A eficácia dos direitos fundamentais: Uma teoria geral dos direitos fundamentais na perspectiva constitucional. Porto Alegre: Livraria do Advogado.

Sêda, E. (1991). O novo direito da criança e do adolescente. Campinas: Governo do Brasil.

Silva, L. M. P., Ferriani, M. G. C., \& Silva, M. A. I. (2012). O poder judiciário como última instância de proteção às crianças e aos adolescentes: Ações intersetoriais, investimento em recursos humanos e estruturação dos serviços. Revista Latino-Americana de Enfermagem, 20(3), 444-452. Recuperado em 30 de junho de 2014, de http://www.scielo.br/scielo.php?script=sci_arttext\&pid=S0104-

$11692012000300004 \&$ Ing $=$ pt\&tlng $=$ pt.

$10.1590 / 50104-$ 11692012000300004 .

Warburton, J. (2001). Prevención, protección y recuperación. Trabalho apresentado no II World Congress Against the Commercial Sexual Exploitation of Children, Yokohama, Japão.

Zaluar, A. (1997). Exclusão e políticas: dilemas teóricos e alternativas políticas. Revista Brasileira de Ciências Sociais, 12(35), 29-45.

Contato: wilsonpsycho@yahoo.com.br, jfalberto@uol.com.br, santosvm09@hotmail.com, kahynalb@hotmail.com, suzany_ludimila@hotmail.com

Recebido em: 16/04/2014

Revisado em: 02/06/2014

Aceito em: 11/08/2014 